Center for Research on Economic and Social Theory CREST Working Paper

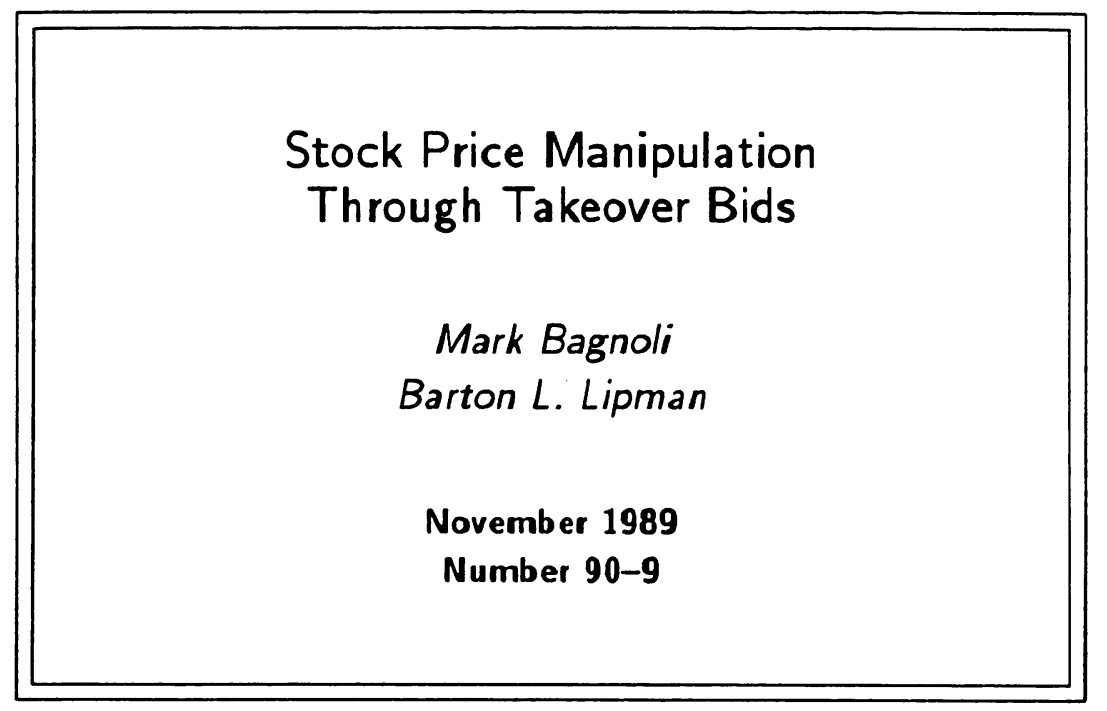

DEPARTMENT OF ECONOMICS University of Michigan Ann Arbor, Michigan 48109
The Sumner and Laura Foster Library The University of Michigad

FEB 201990 



\title{
Stock Price Manipulation Through Takeover Bids*
}

)

by

\author{
Mark Bagnoli \\ University of Michigan
}

and

\author{
Barton L. Lipman \\ Carnegie Mellon University
}

November, 1989

- We wish to thank Sugato Bhattacharyya, Michael Fishman, Rick Green and Milton Harris for helpful comments. As always, we are responsible for any errors. 

“While Mr. Trump's takeover proposal caused AMR's stock price to climb $20 \%$ to $\$ 99.875$, many takeover speculators said yesterday they were unconvinced that Mr. Trump's bid is in fact a serious one. In one sign of market skepticism, the stock's closing price was well below Mr. Trump's $\$ 120$ bid.

"The question we have is: "Is Trump selling the stock today?"' said an arbitrager at another major Wall Street firm."

Wall Street Journal, 6 October, 1989.

\section{Introduction}

When a takeover bid is announced, when someone announces the acquisition of a substantial position in a firm, or when a major stockholder announces his or her views on how the company should be operated, ${ }^{1}$ one generally observes significant changes in the firm's stock price. It is clear that the announcer is aware of this effect and may make the announcement because of this effect. For example, many observers were concerned that Trump's bid for AMR was not really serious, that he was interested in taking advantage of the announcement effect. In fact, Trump recognized this possibility and made additional announcements designed to alleviate this skepticism.

The possibility that a takeover bid is designed solely to allow the bidder to drive up the stock price, sell his holdings at the higher price and drop the bid has not been studied nor incorporated into analyses of takeovers. The purpose of this paper is to explore the viability of this type of manipulation and its effects on takeover attempts. ${ }^{2}$

While baldly dropping the bid after selling the initial position is of dubious legality, a bidder commonly attaches many conditions to the bid which enable him to legally withdraw it. For example, of the top 25 cancellations of 1985 , ten were canceled because conditions of the bid were not met. ${ }^{3}$ As an example of such conditions, Edelman's offer for Fruehauf included stipulations regarding financing availability and the number of shares tendered, along with the following remarkably broad proviso:

1 Here, we are thinking of announcements such as Icahn's preference for a restructuring of USX. See Wall Street Journal, 6 October, 1989.

2 Benabou and Laroque [1989] is the only paper that we are aware of that considers a form of manipulation. The most important differences between their model and ours is that their manipulator simply makes a public announcement at no cost and that there is an exogenously given probability that he speaks the truth. There is a growing literature on related practices such as informed speculation (see Admati and Pfleiderer [1988] and Kyle [1989]), and insider trading (Mirman and Samuelson [1988], Fishman and Hagarty [1989] and Ausubel [1989]). The difference between manipulation and these other practices is that manipulation involves publicly observable actions designed to alter the stock price.

3 The remaining fifteen were canceled either because the bidder lost the bidding contest or because of the target's defensive responses. See Mergers and Acquisitions Almanac, 1986. 
Purchaser is not required to accept shares if any change occurred or is threatened in business, properties, assets, liabilities, capitalization, shareholders' equity, financial conditions, operations, licenses or franchises, results of operations or prospects of Company, its subsidiaries or purchaser which in the sole judgment of the purchaser is or may be materially adverse to the company or if the purchaser becomes aware of any fact, occurance or proposed occurance which, in the sole judgment of the purchaser, is or may be materially adverse with respect to the value of the Company or its subsidiaries, or the value of the shares to the Purchaser.

For the bidder to be able to manipulate the target's stock price he must be able to drop the bid but he must also be able to sell his shares before dropping the bid. This is possible so long as the SEC does not deem it manipulation. ${ }^{4}$ Since it is extremely difficult to assess intent and since the bidder can enlist the aid of others to sell stock, ${ }^{5}$ it is clear that manipulation is possible.

The important features of our model are the following. First, the value of the firm if control is transferred to the bidder is known only to the bidder, not to any other market participant. Second, the bidder can buy shares in the market before announcing the bid. Third, consistent with current regulations, the bidder is permitted to sell his shares but not buy any in the market after making a bid. Finally, we model the market for the target firm's shares by assuming that there are perfectly competitive market makers and noise traders.

We will show that there is a unique equilibrium which can take one of three forms depending predominantly on how costly it is to bid. In equilibrium, the possible bidder valuations are divided into four intervals, which we will refer to by the action chosen by the bidder if his valuation is in that range. If the bidder's valuation is in the lowest interval, he is inactive-that is, he does not acquire a stake in the firm. The next lowest interval contains the manipulators. If the bidder's valuation is in this range, he acquires a stake in the target, bids, sells his shares in the market, and drops his bid. The next interval contains the investors-bidders who acquire an investment position in the target but do not bid. Finally, the high valuations are the serious bidders. If the bidder's valuation is in this interval, he acquires a stake in the target firm, makes a takeover bid and does not drop the bid.

In the unique equilibrium, the inactive and serious intervals are always nonempty. However, one of the other two intervals can be empty and we will distinguish the forms of the equilibrium by which is nonempty. Hence, we have the possibility of an equilibrium with only investors, referred

4 It is our understanding that if the bidder holds less than about $20 \%$ of the target firm's shares, he can sell them while the bid is open.

s Recall Boesky's use of Jefiries in his illegal activities. 
to as an i-form, the possibility of an equilibrium with only manipulators, referred to as an $\mathrm{m}$-form and the possibility of an equilibrium with both, referred to as an im-form.

If it is quite costly to bid, manipulation will never be profitable and so we will have an i-form equilibrium. In this form, only serious bidders bid and so the stockholders know that the bid will not be dropped. As a result, the target firm's stock price rises to the bid. For lower bidding costs, either investing or manipulation may occur and so we will have an im-form equilibrium. If the bidding costs are still lower, manipulation is so profitable that in vesting is never optimal and so we will have an $\mathrm{m}$-form equilibrium. When a bid is made in either of these two types of equilibrium, it signals that the bidder is either serious or a manipulator. If the stockholders could determine the motivation for the bid, then the stock price would accurately reflect the bidder's intentions and the manipulator would earn no profits. Hence, to earn profits, the manipulator must emulate the behavior of a serious bidder and so chooses the same bid. As a result, the stock price rises when a bid is made because of the possibility that the bid was made by a serious bidder. However, the stock price remains lower than the bid because of the possibility of manipulation.

We can use our model to assess the impact of a prohibition on manipulation. ${ }^{6}$ If manipulation is prohibited, the bidder is either inactive, an investor or a serious bidder. Clearly, if the bidding costs are such that the bidder would not have chosen to manipulate, then the prohibition has absolutely no effect. The prohibition alters behavior in either of the other forms of equilibrium because the most profitable action for some valuations is no longer permitted.

In an im-iorm equilibrium, a would-be manipulator chooses to be inactive if his valuation is relatively low and invests otherwise. In the $\mathrm{m}$-form equilibrium, the would-be manipulator chooses to invest if his valuation is relatively low and chooses to make a serious bid otherwise. Since the response differs depending on the form of the equilibrium, the consequences of a prohibition depend on the form of equilibrium.

In an im-form, the prohibition does not affect the set of valuations for which the bidder makes a serious bid and so the only effect comes from the knowledge that if a bid is made, then the bidder is serious. As a result, after a bid is made, the stock price rises to the bid. In an m-form equiiibrium, a prohibition on manipulation has two important additional effects. First,

- In the context of our model, such a prohibition would be equivalent to a prohibition on selling shares in the open market if a bidder has an ontstanding takeover bid. 
the prohibition leads to some efficient takeovers occurring when otherwise, they would not have. The reason is that the prohibition induces the bidder to make a serious bid rather than manipulate for certain valuations. As we will show, these additional takeovers are always efficient. Second, and related, the prohibition will result in a lower bid. Therefore, prohibiting manipulation benefits a serious bidder in an $\mathrm{m}$-form equilibrium. Further, it has no effect on a serious bidder in either of the other two forms. Hence, we conclude that such a prohibition weakly benefits a serious bidder and weakly increases the probability that an efficient takeover bid is made.

To assess the impact of a prohibition on the target firm's stockholders, we assume that prior to the bid, they do not know whether or not they will be one of the noise traders-that is, they may have to sell their shares for "liquidity" reasons. We show that whether manipulation is prohibited or not, the stockholder's expected payoff per share conditional on not being a noise trader is exactly the expected value of the target's share prior to the arrival of the bidder. The per share expected payoff to a noise trader is smaller when manipulation is possible because the price she receives for her shares is below the expected value of the stock. The loss to the noise traders is the source of the manipulator's profits. Hence, ex ante (prior to learning if she will be a noise trader), each stockholder prefers the prohibition on manipulation.

One important consequence of such a prohibition will be its effects on the incentives of potential bidders to search for potential targets. Intuitively, prohibiting manipulation eliminates one possible source of profits from bidding, suggesting that a prohibition decreases the amount of search that is done. However, the situation is not that simple. The prohibition decreases the profits of manipulators, does not affect investors, and may increase the profits of serious bidders. Therefore, if the bidder has some prior information about the value of the firm under his control, the prohibition decreases search by a bidder who is likely to have a relatively low valuation and increases search by a bidder who is likely to have a relatively high valuation. The possibility of manipulation results in a social loss because of the reduction in the probability of an efficient takeover occurring and, since search is costly, from rent seeking by the low valuation bidders. However, one must be careful to realize that this conclusion requires that the bidder have prior information about the value of the target under his control. In the absence of prior information, the prohibition may discourage search. If so, there way be a trade-off between providing incentives to search and generating efficient outcomes given that search has occurred.

Thus, the prohibition weakly benefits the serious bidder, weakly increases the chances of an 
efficient takeover, weakly benefits the target firm's stockholders, and does not affect the market makers (they are perfect competitors). Further, if the bidder has prior information about the value of the target under his control, the prohibition encourages efficient search and discourages inefficient search.

The paper is organized as follows. The model and its equilibrium are described in section 2. In section 3, we explain the effects of prohibiting manipulation and describe the properties of the equilibrium. In section 4 , we offer some concluding remarks.

\section{The Model}

We assume that there is one potential bidder, whom we will refer to as Ted. He has learned that the per share value of the target if he acquired control would be $y$. This value is his private information and is not known by the current stockholders of the target firm nor any other potential participant in the market for the target's shares. The per share value of the target if control is not transferred is $x$ which is unknown to all. Since the target firm's assets are used by whoever controls it, $x$ and $y$ can be thought of as correlated random variables. We assume that they are related in the following ways.

Both $x$ and $y$ have finite supports, $[\underline{x}, \bar{x}]$, and $[\underline{y}, \bar{y}]$ respectively. We assume that $\bar{y}>\mathrm{E}[\boldsymbol{x} \mid$ $y=\bar{y}], \underline{y}<\mathrm{E}[x \mid y=\underline{y}]$ and that $\mu \equiv \mathrm{E}[x]=\mathrm{E}[x \mid y=\mu]$. We also assume

$$
0<\frac{d \mathrm{E}\left[x \mid y=y^{\prime}\right]}{d y^{\prime}}<1
$$

This assumption guarantees that learning that $y$ is high is good news but not too good. The idea is that since both the current management and Ted intend to use the same assets, some but not all of an increase in Ted's valuation should be attributed to the value of those assets and should be reflected in an increase in the expected value of a share under current management. We also assume that ${ }^{7}$

$$
0<\frac{d \mathrm{E}\left[x \mid y \geq y^{\prime}\right]}{d y^{\prime}}<1
$$

Before discussing our other technical assumptions, we will describe the sequence of decisions. As we stated above, we assume that Ted has already learned his valuation-we do not model the

7 It is not difficult to show that (1) and (2) are independent assumptions. 
information acquisition choice explicitly. After learning his valuation, he can acquire a position in the target firm. Next, he is permitted to make a takeover bid. After the bid is made, the market for the target's stock opens and trade in the firm's stock is permitted. When the market closes, Ted then decides whether or not to drop the bid. If he does not drop the bid, then the current stockholders of the target firm make their tendering decisions.

In stage 1, Ted decides how many shares in the target firm, if any, to acquire in the market. We assume that he cannot acquire more than $\bar{k}$ shares and that he can purchase shares at $\mu(=\mathrm{E}[x])$. We make the former assumption because current SEC regulations require that one must announce one's holdings within ten days of having acquired $5 \%$ of a firm's outstanding shares. This results in a limit on the number of shares that can be acquired before the bidder's presence is made known to the market. The latter assumption, that these shares can be acquired at the expected value of $x$, is equivalent to assuming that the market participants believe that there is an infinitesimal probability that a bidder will appear for any particular firm.

In stage 2 , if Ted chooses to bid, he is assumed to make an any-and-all bid of $b$ for the target. As a result, if the stockholders actually get to tender their shares to Ted, they know that he will purchase every share tendered at $b$. We also assume that Ted can exclude ${ }^{8}$ minority stockholders from enough of the increase in the value of the firm so that a minority stockholder receives $z \leq \mu$ per share. ${ }^{9}$ We assume that there is a strictly positive cost of bidding that depends on the bidder's valuation, $c(y)$, where $c^{\prime}(y)<0$. Intuitively, we are assuming that part of Ted's cost of bidding involves trying to prove that he is serious about acquiring the target. The higher is Ted's valuation, the less difficult it is for him to appear to be a serious bidder. We will also assume that $\bar{k} \frac{d \mathrm{E}\left[x \mid y=y^{\prime}\right]}{d y^{\prime}}+c^{\prime}(y)>0$ and that $c(\bar{y})<N(\bar{y}-\mathrm{E}[x \mid y=\bar{y}]) .^{10}$

In stage 3 , trade in the target's stock occurs. We assume that there are $M \geq 2$ competitive market makers in the firm's stock each of whom quotes a price he will buy shares at and a price he will sell shares at. We will refer to these as the buying and selling prices, respectively. ${ }^{11}$ Each

- For a discussion of the effects of exclusion, see Bagnoli and Lipman [1988].

- Little in our analysis would change if Ted was assumed to make a conditional bid for $100 \%$ of the shares or if he is assumed to make a two-tiered bid with a lower back end price. Only small differences arise in the analysis of the tendering decisions of the stockholders.

10 The former implies that as $y$ increases, Ted's profits from manipulation rise slower than his proits from taking an investment position. The latter implies that if $y=\bar{y}$, then Ted prefers to acquire control of the target rather than take an investment position.

11 Of course, it.is more common in the literature to refer to these as bid and asks. We do not do 80 in order to 
market maker stands ready to meet all demand and supply at the prices he quotes and tenders any shares that remain in inventory optimally. Any current stockholder can choose to sell shares in the market and any potential investor is permitted to buy shares. While a bid is outstanding Ted is prohibited from acquiring shares in the market but he is permitted to sell his shares. ${ }^{12}$ However, we do not permit him to sell short. We also assume that there are noise traders in this market. That is, some stockholders choose to sell their shares for reasons that remain unmodelled. We assume that the number of shares these traders sell is random with expectation $\gamma>0$, the only important aspect of the noise trading for our analysis. ${ }^{13}$

In stage 4, Ted is permitted to withdraw his bid, i.e., drop the takeover attempt. If he does not drop his bid, then, in stage 5 , the stockholders choose how many shares to tender. We assume that there are $N$ shares of the target firm outstanding and that $K$ is the number of shares needed to obtain control of the target. We assume that $K>N / 2$ and that Ted's holdings are not so large that he has already acquired controlling interest in the target $(K>\bar{k})$.

The payoffs are as follows. Each stockholder is risk neutral and her payoff is the sum of the value of any shares not sold plus the payments received for any shares sold either in the market or to Ted, less any payments for shares purchased in the market. Each market maker's payoff is simply the profits earned. Ted pays $\mu$ per share for his original position, the cost of bidding if he makes a bid, and $b$ per share for shares tendered to him. He receives the payments for any shares sold in the market and the value of any shares held.

We will seek a sequential equilibrium to the game. A sequential equilibrium is a vector of strategies and beliefs for the players such that each player's strategy is a best reply given the beliefs and the strategies of the other players. Further, whenever possible; the beliefs must satisfy Bayes' rule. We impose a further restrictioil on beliefs which is essentially the same as Grossman and Perry's [1986] perfect sequential equilibrium. In the text, we describe the unique equilibrium and provide intuition for it. The technical details are relegated to the Appendix.

As is usual, the game is solved backwards. Let $x^{e}$ be the expectation of $x$ given what the stockholders have observed up to stage 5 including that the bid has not been dropped. To simplify

avoid potential confusion between the market maker's bid and Ted's takeover bid.

12 As we mentioned above, these restrictions conform with current regulation.

13 None of the analysis is altered if $\gamma$ is a function of either the bid or the buying price. 
the discussion, we restrict attention in the text to the case where $b \geq x^{e} \geq \mu$. As shown in the Appendix, this will hold in equilibrium. To see intuitively why it holds, recall that the value of the target if it remains independent is positively correlated with Ted's valuation. Since the observation of a bid that is not dropped is good news about $y$, it is good news about $x$. Hence, $x^{e} \geq \mu$. The reason that the bid exceeds $x^{e}$ is that the stockholders will not sell shares to Ted if he bids less than this.

Given that $b \geq x^{e} \geq \mu$, stages 4 and 5 are quite simple. Recall that $\mu \leq z$. Hence, in stage 5 , each stockholder can either choose to sell a share for $b$ or hold it and have it become worth either $x^{e}$ if Ted fails or $z$ if he succeeds. Since both are less than the bid, each stockholder has a dominant strategy-tender every share. Given this, in stage 4 , if Ted continues with the bid, he purchases all of the remaining shares. Our assumptions guarantee that there is a critical valuation, $y^{*}$, such that if $y \geq y^{*}$, Ted continues the bid and drops it otherwise.

Backing up to stage 3, we need to determine how many shares Ted sells while the market for the target's stock is open. To do this, we must determine the price at which he can sell shares. A market maker's expected profits as a function of his selling price $p_{s}$ and his buying price $p$ are

$$
\mathrm{E}\left[n_{s}\left(p_{s}-v_{s}\right)+n_{b}\left(v_{b}-p\right)\right]
$$

where $n_{b}\left(v_{b}\right)$ and $n_{s}\left(v_{s}\right)$ are the number (value) of shares he buys and sells respectively. Competition ensures that $\mathrm{E}\left[n_{s}\left(p_{s}-v_{s}\right)\right]=0$ and that $\mathrm{E}\left[n_{b}\left(v_{b}-p\right)\right]=0 .{ }^{14}$

The former requires that $p_{s}^{*}=\frac{E\left[n_{,} v_{s}\right]}{E\left[n_{s}\right]}$. Since, in equilibrium, the market makers will charge the same price, the number of shares a market maker sells is his share of total demand. Also, $n_{s}$ conveys no information about $v_{s}$ because the only person with private information cannot buy shares. Thus, $\mathrm{E}\left[n_{s} v_{s}\right]=\mathrm{E}\left[n_{s}\right] \mathrm{E}\left[v_{s}\right]$ and so the equilibrium selling price is $p_{s}^{*}=\mathrm{E}\left[v_{s}\right] . \mathrm{E}\left[v_{s}\right]$ is simply the probability that the bid is continued given that it was made times $b^{15}$ plus the probability that the bid is dropped times the expected value of a share in this event which we designate as $w$. Therefore,

$$
p_{s}^{*}=\phi b+(1-\phi) w
$$

where $\phi$ is the probability that the bid is not dropped given that it was made.

\footnotetext{
14 Assuming that the market makers play a Bertrand game would generate the same equalities.

18 Recall that when $b \geq x^{e} \geq x$, the stockholders tender every share if they have the opportunity.
} 
Turning to the equilibrium buying price, competition ensures that $p^{*}=\frac{E\left[n_{b} v_{b}\right]}{E\left[n_{b}\right]}$. With probability $\phi$, Ted does not drop the bid, in which case $v_{b}=b$. In the event that he drops the bid, $v_{b}=w$, so $E\left[n_{b} v_{b}\right]$ is just $\phi b$ times the expected number of shares sold to the market maker given that Ted does not drop the bid plus $(1-\phi) w$ times the expectation of $n_{b}$ conditional on Ted dropping the bid. Thus, we must analyze Ted's decision to sell shares in the market to determine the equilibrium buying price.

It is not hard to show that in equilibrium, $b>w$, so that $p^{*} \leq b$ with equality only if $\phi=1$. So suppose Ted intends to continue with the takeover attempt. If Ted sells shares, he receives less for them than he will pay during the tendering stage. Hence, if Ted intends to continue, he will choose not to sell shares in the market. If he drops the bid, then he receives $\mathrm{E}[x \mid y]$ on any unsold shares and $p^{*}$ on the shares he sells. If $\mathrm{E}[x \mid y]>p^{*}$, then he sells none. This is equivalent to taking an investment position except that he has incurred the costs of bidding. Thus, it could not have been optimal to bid and so, in equilibrium, we must have $p^{*} \geq E[x \mid y]$. In this case, the bidder should sell all of his shares. Therefore, if Ted intends to drop the bid, he will sell all of his shares in the market.

We can now determine the equilibrium buying price. Since, in equilibrium, all of the market makers will offer the same buying price, the expected number of shares bought when Ted is not going to drop the bid is this market maker's expected share of the shares sold by noise traders, $\gamma / M$. Ted will sell all of his initial position, $k$, if he is planning to drop the bid and so the expected number of shares bought by the market maker is $\frac{\gamma+k}{M}$. This means that the equilibrium buying price is

$$
p^{*}=\frac{\mathrm{E}\left[n_{b} v_{b}\right]}{\mathrm{E}\left[n_{b}\right]}=\frac{\phi \gamma}{\gamma+(1-\phi) k} b+\frac{(1-\phi)(\gamma+k)}{\gamma+(1-\phi) k} w \equiv \hat{\phi} b+(1-\hat{\phi}) w
$$

Notice that $p^{*}$ can be interpreted as the expected value of a share given that the market maker can purchase it. Since it is easier to purchase shares when Ted is selling his initial position and since Ted sells his position only if he intends to drop the tid, there is a lemon's problem. ${ }^{16}$ Being able to buy shares is bad news. Hence, the probability that Ted continues the bid, $\phi$, exceeds the probability that he continues given that a share can be acquired, $\hat{\phi}$.

Backing up to stage 2, we must determine Ted's optimal bidding strategy. He can choose

16 This feature is standard in microstructure models. See, for example, Glosten and Milgrom [1985] or Admati and Pfleiderer [1988]. 
whether or not to bid and, if he bids, whether or not to subsequently drop the bid. Thus, Ted can obtain one of three payoffs - the payoff from bidding and not dropping, the payoff from bidding and dropping, and the payoff from not bidding.

If Ted is a serious bidder, he does not sell shares in the market, does not drop the bid, and acquires all outstanding shares. Hence, his payoff is

$$
\pi^{c}(y)=N y-(N-k) b-c(y)-k \mu \text {. }
$$

If Ted is an investor, his payoff is

$$
\pi^{i}(y)=k \mathrm{E}[x \mid y]-k \mu
$$

and if Ted is a manipulator, his payoff is

$$
\pi^{m}(y)=k p^{*}-c(y)-k \mu
$$

In stage 1 , Ted chooses to acquire a position if one of the three payoffs written above is positive. In every case, if Ted's payoff is positive, it increases in $k$. The reasons are the following. If Ted is a serious bidder, he is able to buy the original position at a lower per share price than the bid. Since he will end up with all of the shares, he is better off if he purchases as many as he can at the lower price. If Ted is an investor, it must be true that $\mathrm{E}[x \mid y]>\mu$ and so he is better off the more shares he acquires. If Ted is a manipulator, he intends to sell his initial position and drop the bid. If the payoff from doing this is positive, he is selling the shares for more than he paid for them and so he is better off the more shares he acquires. Hence if Ted acquires an initial position, he acquires $\bar{k}$ shares.

Since each of these three potential payoffs depend on Ted's valuation, we will need to know how each varies with $y$ in order to determine his best action. Holding $b$ and $p^{*}$ constant, our assumptions on $c$ and the conditional distribution of $x$, imply that

$$
\frac{\partial \pi^{c}}{\partial y}>\frac{\partial \pi^{i}}{\partial y}>\frac{\partial \pi^{m}}{\partial y}>0 .
$$

Since $\pi^{c}$ is steepest, there is a critical value, $y_{c}$, such that $\pi^{c}(y) \geq \max \left\{\pi^{i}(y), \pi^{m}(y)\right\}$ if and only if $y \geq y_{c}$. This is the set of valuations for which Ted is a serious bidder. Analogously, let $y_{i}$ be the smallest valuation for which Ted's optimal action is to invest and $y_{m}$ the smallest valuation 
for which Ted manipulates. (These valuations are left undefined if the relevant action is never optimal.)

If Ted's valuation exceeds $y_{c}$, he seeks to acquire control of the target by making a bid which is at least the expected value of a share under current management given that the stockholders have observed that he has made a bid and chosen not to drop it. This conditional expectation is simply $\mathrm{E}\left[x \mid y \geq y_{c}\right]$. Since the serious bidder wishes to acquire the shares at the lowest possible price, he chooses $b=\mathrm{E}\left[x \mid y \geq y_{c}\right]$ regardless of his valuation.

Figures 1-3 show possible configurations of Ted's payoffs. The different figures will correspond to the different forms of equilibrium referred to in the introduction. In every figure, Ted's optimal action, as a function of his valuation, is determined by the upper envelope of the three payoff curves. Figure 1 is drawn under the assumption that this upper envelope does not contain $\pi^{m}$ and so corresponds to an $\mathrm{i}$-form equilibrium. Figure 2 is drawn under the assumption that the upper envelope contains all three payoffs and so corresponds to an im-form equilibrium. Figure 3 is drawn under the assumption that the upper envelope does not contain $\pi^{i}$ and so corresponds to an $\mathbf{m}$-form equilibrium.

So, consider figure 1 , an i-form equilibrium. Since $\pi^{m}$ is not part of the upper envelope, Ted will not manipulate regardless of his valuation. For low valuations, those between $\underline{y}$ and $y_{i}$, Ted does not acquire a position in the firm. If $y$ is between $y_{i}$ and $y_{c}$, Ted is an investor. Finally, if $y \geq y_{c}$, he is a serious bidder. Since no bid is dropped, the equilibrium buying price is the bid.

Now, consider figure 2, an im-form equilibrium. It differs from figure 1 in that both $\pi^{i}$ and $\pi^{m}$ are part of the upper envelope. Hence there is now a set of valuations for which manipulation yields the highest profits. If $y$ is less than $y_{m}$, then, as before, Ted does not acquire a position in the firm. If $y$ is between $y_{m}$ and $y_{i}$, he is a manipulator. If $y$ is between $y_{i}$ and $y_{c}$, then Ted is an investor. Finally, if $y \geq y_{c}$, he is a serious bidder.

As discussed above, a serious bidder always bids $b=\mathrm{E}\left[x \mid y \geq y_{c}\right]$. Clearly, if the market believes that a bid is made solely for the purpose of manipulating the stock price, the equilibrium buying price will be $\mu$ which is less than $b$. Hence to maximize manipulation profits, Ted must emulate a serious bidder and so will bid $b=E\left[x \mid y \geq y_{c}\right]$. Thus when this bid is observed, the market can only infer that Ted is either a manipulator or a serious bidder-that is, that $y \in\left[y_{m}, y_{i}\right)$ 
or that $y \geq y_{c}$. Using (3), then, the equilibrium buying price is

$$
p^{*}=\hat{\phi} \mathrm{E}\left[x \mid y \geq y_{c}\right]+(1-\hat{\phi}) \mathrm{E}\left[x \mid y \in\left[y_{m}, y_{i}\right)\right]
$$

where $\hat{\phi}=\gamma \phi /[\gamma+(1-\phi) k]$ and $\phi=\operatorname{Pr}\left[y \geq y_{c} \mid y \geq y_{c}\right.$ or $\left.y \in\left[y_{m}, y_{i}\right)\right]$.

Finally, consider figure 3, an $\mathrm{m}$-form equilibrium. It differs from the previous two figures in that $\pi^{i}$ is no longer part of the upper envelope. Again, if $y$ is less than $y_{m}$, Ted does not acquire a position in the firm. If $y$ is between $y_{m}$ and $y_{c}$, he is a manipulator. Finally, if $y \geq y_{c}$, he is a serious bidder. As in the previous case, Ted bids $b=\mathrm{E}\left[x \mid y \geq y_{c}\right]$ if he is a manipulator or a serious bidder. Again, using equation (3), the equilibrium buying price is

$$
p^{*}=\hat{\phi} \mathrm{E}\left[x \mid y \geq y_{c}\right]+(1-\hat{\phi}) \mathrm{E}\left[x \mid y \in\left[y_{m}, y_{c}\right)\right]
$$

where $\phi=\operatorname{Pr}\left[y \geq y_{c} \mid y \geq y_{m}\right]$.

Notice that the differences in the three figures arise from differences in the payoffs that determine the upper envelope. Looking at their definitions, we see that which figure arises depends on the costs of bidding. If the costs of bidding are high (meaning that $\pi^{m}$ is not part of the upper envelope), we obtain an i-form equilibrium. If the costs of bidding are lower so that both $\pi^{i}$ and $\pi^{m}$ are part of the upper envelope, we obtain an im-form equilibrium. If the costs are still lower, $\pi^{i}$ is not part of the envelope and so we obtain an $\mathrm{m}$-form equilibrium. Summarizing,

Theorem 1: There is a unique equilibrium and, depending on the parameter values, it is either an i-form, an im-form or an m-form equilibrium.

The proof is in the appendix.

\section{Predictions}

In this section, we present comparative static results and highlight some of the properties of the equilibrium. The three exogenous variables of greatest interest are the maximum size of Ted's initial position, $\bar{k}$, the total number of outstanding shares in the target, $N$, and the expected volume of noise trading, $\gamma$.

An increase in the expected volume of noise trading makes it harder for the market maker to infer Ted's actions. Since there is no manipulation in an i-form equilibrium, this has no effect. 
However, in either an im-form or an $m$-form equilibrium, it is easy to show that $p^{*}$ increases with an increase in $\gamma$ as does the set of valuations for which Ted manipulates. In the $\mathrm{m}$-form, this has surprising consequences. In particular, the equilibrium bid rises and the probability that a serious bid is made declines when the volume of noise trading increases. The reason is that, in an $\mathrm{m}$-form, the lowest valuation that makes a serious bid is indifferent between acquiring and manipulating. Therefore, anything that makes manipulation profits rise, such as an increase in $\gamma$, makes the bidder's desire to take over the firm a more positive signal about $y$ and hence about $x$. As a result, a serious bidder must pay more to acquire the firm.

The consequences of an increase in $N$ or $\bar{k}$ are ambiguous. To show this, we present a simple numerical example of an im-form equilibrium. In this example, $y$ is uniformly distributed on [0,2], $x=\frac{1}{2} y+\epsilon$ and $\epsilon$ is independent of $y$ and distributed uniformly on [0,1]. Hence $\mu=1$. Finally, assume that $c(y)=a_{0}-a_{1} y$.

Increases in $N$ can be interpreted as the effect of considering a takeover attempt on a more valuable target. As can be seen from Table 1, unambiguous predictions about the effect of increasing $N$. In Table 1, within each pair of rows, all parameters except $N$ are held constant. In the first pair of rows, the increase in $N$ raises $y_{c}, b, y_{i}$, and $p^{*}$ and lowers $y_{m}, \phi$ and $\hat{\phi}$. In the second pair, $y_{i}, y_{m}$ and $p^{*}$ move in the opposite direction. The final pair show that an increase in $N$ has an ambiguous effect on $y_{c}, b, \phi$ and $\hat{\phi}$. Hence, we can draw no conclusions about the effect of $N$ on the probability of manipulation, the profits from it, the post-bid stock price, or the bid.

TABLE 1

\begin{tabular}{|c|c|c|c|c|c|c|c|c|c|c|c|}
\hline$N$ & $\bar{k}$ & $a_{0}$ & $a_{1}$ & $\gamma$ & $y_{c}$ & $b$ & $y_{i}$ & $y_{m}$ & $p^{*}$ & $\phi$ & $\hat{\phi}$ \\
\hline 10 & 5 & 2 & 1 & 5 & 1.31 & 1.327 & 1.065 & 0.902 & 1.2196 & 0.808 & 0.678 \\
100 & 5 & 2 & 1 & 5 & 1.33 & 1.333 & 1.066 & 0.901 & 1.2199 & 0.802 & 0.669 \\
\hline 40 & 30 & 2 & 1 & 5 & 1.15 & 1.29 & 1.019 & 0.733 & 1.0422 & 0.749 & 0.298 \\
400 & 30 & 2 & 1 & 5 & 1.32 & 1.33 & 1.018 & 0.743 & 1.0419 & 0.712 & 0.261 \\
\hline 40 & 5 & 2 & 0.5 & 5 & 1.35 & 1.338 & 1.0073 & 0.971 & 1.3029 & 0.947 & 0.899 \\
400 & 5 & 2 & 0.5 & 5 & 1.34 & 1.334 & 1.0067 & 0.973 & 1.3027 & 0.952 & 0.908 \\
\hline
\end{tabular}

The last interesting comparative static is the effect of an increase in $\bar{k}$. The SEC has, at least, partial control over the number of shares that Ted can acquire before making a takeover bid. In 
our model, as can be seen in Table 2 , an increase in $\bar{k}$ has ambiguous effects. In particular, $y_{m}, y_{i}$ and $\phi$ are not monotone in $k$.

\section{TABLE 2}

\begin{tabular}{|c|c|c|c|c|c|c|c|c|c|c|c|}
\hline$N$ & $\bar{k}$ & $a_{0}$ & $a_{1}$ & $\gamma$ & $y_{c}$ & $b$ & $y_{i}$ & $y_{m}$ & $p^{*}$ & $\phi$ & $\hat{\phi}$ \\
\hline 50 & 6 & 2 & 0.5 & 10 & 1.34 & 1.335 & 1.019 & 0.904 & 1.258 & 0.851 & 0.781 \\
50 & 10 & 2 & 0.5 & 10 & 1.32 & 1.331 & 1.027 & 0.761 & 1.162 & 0.718 & 0.560 \\
50 & 15 & 2 & 0.5 & 10 & 1.30 & 1.325 & 1.022 & 0.691 & 1.110 & 0.679 & 0.459 \\
50 & 20 & 2 & 0.5 & 10 & 1.27 & 1.318 & 1.018 & 0.667 & 1.083 & 0.675 & 0.409 \\
50 & 25 & 2 & 0.5 & 10 & 1.24 & 1.311 & 1.014 & 0.659 & 1.067 & 0.680 & 0.378 \\
50 & 35 & 2 & 0.5 & 10 & 1.18 & 1.295 & 1.010 & 0.662 & 1.048 & 0.702 & 0.344 \\
\hline
\end{tabular}

To explain the effects of manipulation, we contrast our equilibrium to the equilibrium when manipulation is prohibited. In our simple model, this can be accomplished by prohibiting the sale of shares by an individual while he has a takeover bid outstanding. In this case, one of the options available in our model disappears. Tracing the consequences, we see that Ted's actions will now be defined by which of $\pi^{c}(y), \pi^{i}(y)$ and 0 (the profits from inactivity) is largest. In equilibrium, the critical values $y_{i}$ and $y_{c}$ are defined by the same equations as in an i-form equilibrium and so the equilibrium when manipulation is prohibited is qualitatively similar to an $\mathrm{i}$-form equilibrium. This immediately implies that if the costs of bidding are so large that we achieve an $\mathrm{i}$-form equilibrium when manipulation is possible, then there are no effects of a prohibition.

Alternatively, suppose that when manipulation is permitted, we have an im-form equilibrium. Prohibiting manipulation alters $y_{i}$ but not $y_{c}$. Examining figure 4, one sees that $y_{m}<y_{i}^{\prime}<y_{i}$. In other words, the prohibition causes some of the manipulators, $y \in\left[y_{m}, y_{i}^{\prime}\right)$, to choose to be inactive and the others, $y \in\left[y_{i}^{\prime}, y_{i}\right)$, to be investors.

In an $\mathrm{m}$-form equilibrium, the critical value for continuing with the bid falls and the critical value for acquiring a position in the target rises as can be seen in figure 5 . This means that a prohibition on manipulation induces Ted to acquire control for lower valuations than he otherwise would. One can show that $y_{c}>\mathrm{E}\left[x \mid y_{c}\right]>\mu$ where $\mu$ is the unconditional expectation of the value of the firm under current management. This means that when manipulation is prohibited, more efficient takeovers are undertaken. Since $b=\mathrm{E}\left[x \mid y \geq y_{c}\right]$, the decrease in $y_{c}$ due to the prohibition on manipulation implies that $b$ falls. This makes Ted better off if he is a serious bidder. 
Turning to the effects on the stockholders, recall that we have assumed that they do not know in advance whether or not they will be noise traders. From an ex ante point of view, conditional on not being a noise trader, the stockholder's expected payoff per share is $\mu$. To see this notice first that if Ted takes over the firm, the stockholder receives the expectation of $x$ conditional on this event per share. In any other event, the stockholder retains his shares and hence receives the expectation of $x$ conditional on this event per share. Thus, conditional on not being a noise trader, the stockholders do not care whether manipulation is prohibited or not. However, due to the lemon's problem created by manipulation, a noise trader's expected payoff per share is less than $\mu$. Hence, prior to learning whether she will be a noise trader, each stockholder prefers the prohibition on manipulation.

Lastly, we can determine the effects of prohibiting manipulation on Ted's willingness to acquire information about potential targets. We showed that prohibiting manipulation makes Ted better off if his valuation is high because he acquires control with a lower bid. Of course, if Ted intended to manipulate, he is worse off as he must accept an action that yields a lower payoff. Therefore, if Ted has prior information about his valuation before undertaking search, the prohibition encourages search by bidders who are likely to be serious and discourages search by those likely to be manipulators. If search were done in the expectation that Ted would make profits through manipulation, the search costs are a deadweight social loss. Therefore, prohibiting manipulation will result in an increase in social welfare for two reasons. First, those bidders who are likely to undertake an efficient takeover are encouraged to search. Second, those who are likely to engage in socially inefficient search in order to earn profits through manipulation are discouraged. On the other hand, if the bidder does not have private information, it is possible that a prohibition, by eliminating one source of profits, may reduce search.

\section{Conclusions}

In this paper, we have shown that a bidder may earn profits by making a takeover bid solely to manipulate the target firm's stock price. A bidder who intends to manipulate mimics a serious bidder but, instead of completing the takeover attempt, he sells his initial position in the market and then drops the bid. He earns profits because the market cannot tell if the bid is serious, so the market price of the target firm's stock rises.

We have shown that prohibiting manipulation weakly increases the probability of an efficient 
takeover and weakly reduces the equilibrium bid. Thus, a prohibition promotes efficiency and eliminates the transfer of wealth from noise traders to manipulators. However, by eliminating one source of profits, it may reduce the bidder's incentives to search. If the bidder has no prior information, then there may be a trade-off between increasing the probability of a serious bid given that the target has been discovered and lowering the probability of the target being discovered. If, on the other hand, the bidder has prior information, then the prohibition encourages him to search if he is more likely to make a serious bid and discourages search if he is more likely to manipulate.

Clearly, there is much room for further research. For example, in our model, the market for the target firm's stock opens once, after the bid is made. Instead, suppose that the market only opens after the bidder's initial position is revealed but before a bid is actually made. If so, manipulation of a different sort can occur - the manipulator can imitate both a serious bidder and an investor. Presumably, the market interprets the purchase of an initial position as good news about $x$ thereby enabling the manipulator to earn profits and so there should be only minor differences between this and our analysis.

A more interesting possibility, and one that we are currently pursuing, is if trade occurs between the announcement of the acquisition of an initial position and the making of a bid as well as after the bid is made. The analysis of this case is much more complex because the bidder can now choose the manner in which he manipulates the stock price.

Another interesting issue is reputation effects. Suppose that the bidder can make subsequent takeover attempts for other targets, and their value under his control is correlated with the value of the first target. In this case, the outcome of his future attempts may depend on what the bidder reveals from his previous attempts. We have produced an example with two targets in which the bidder acquires the initial target in order to enhance his ability to manipulate the stock price of the second target. However, if the second target were not available, the bidder would have chosen to manipulate the first target's stock price. We are currently pursuing this issue. 


\section{Appendix}

A sequential equilibrium is a vector of strategies and beliefs such that (1) given the beliefs, each player's strategy is a best reply to the other players' strategies and, (2) where possible, the beliefs satisfy Bayes' rule. We consider sequential equilibria which satisfy the following conditions. First, in order to avoid trivial multiplicities, we assume that if a stockholder is indifferent between tendering and not tendering, then he tenders. Second, we assume that if the bidder has bid less than the expected value of $x$, then no stockholder tenders shares. ${ }^{1}$

Finally, we employ a Grossman-Perry type condition on beliefs. More specifically, if the bidder deviates to a strategy that generates an off-the-equilibrium path action, $a$, there is no set of valuations to which such a deviation can be attributed. That is, given the deviation and the action, consider all possible sets of valuations for the bidder. For each such set, say $Y$, compute the stockholders' best reply to the deviation given that they infer only that $y \in Y$. Given that, compute $Y^{\prime}$, the set of $y$ for which the profits from the deviation (given the just computed best reply of the stockholders) exceed their equilibrium path profits. Our condition requires that $Y \neq Y^{\prime}$. Intuitively, if $Y=Y^{\prime}$, the deviation can be interpreted as a credible signal that $y \in Y$. If the stockholders view the deviation in this way, then the deviation is profitable for all $y \in Y$, breaking the proposed equilibrium.

To prove Theorem 1, we begin by noting that, in equilibrium, any bid made must have a positive probability of success. This is true because bidding is costly so if the probability of success is zero, the serious bidder earns negative profits. Recall that the manipulator can only earn profits by emulating the serious bidder. The reason is that if he does not do so, then the market can infer his intent. In this case, the stock price does not rise and so the manipulator earns negative profits too. Thus, in the remainder of the appendix, we restrict our attention to bids that have a positive probability of success. The case when the probability of success is one is straightforward and dealt with in the proof of Theorem 1 . We use the following 5 Lemmas to describe optimal behavior in each stage when the probability of success is strictly between zero and one. Also, let $x^{e}(k, b, \kappa)$ be the stockholders' expected value of a share if control is not transferred to the bidder given that the bidder has acquired $k$ shares, bid $b$ and holds $\kappa$ shares after the market has closed. We will suppress the arguments of $x^{e}$ when no confusion will arise.

Lemma 1: In stage 5 , if $z>b \geq x^{e}$, then the stockholders tender $K-\kappa$ shares. If $b \geq \max \left\{x^{e}, z\right\}$, then all shares are tendered to the bidder. Otherwise, no shares are tendered.

Proof: Suppose that $b \geq \max \left\{x^{e}, z\right\}$. Then it is a dominant strategy to tender every share. If $z>b \geq x^{e}$, then any vector of tendering strategies $\sigma=\left(\sigma_{1}, \sigma_{2}, \ldots, \sigma_{n}\right)$ such that $\sum_{i} \sigma_{i}=K-\kappa$ forms an equilibrium. To see this, consider the $i^{\text {th }}$ stockholder. If she is tendering shares and chooses to tender fewer shares, she causes the takeover to fail. As a result, any untendered shares

1 In this situation, there may also be an equilibrium in which control is transferred to the bidder. This equilibrium seems quite implausible and so we rule it out. 
were worth $z$ and are now worth less, $x^{e}$. Alternatively, if she is not tendering all of her shares and if she tenders additional shares, she loses $z-b>0$ per share. Hence, such a vector of tendered shares is an equilibrium. Similar arguments show that no other vector of pure strategies is an equilibrium. Finally, if $x^{e}>b$, no shares are tendered by one of our equilibrium restrictions. It is easy to see that the restriction has each stockholder choosing a best reply.

Lemma 2: In stage 4 , if $b \geq x^{e}$, then there exists $a y^{*}$ such that the bidder continues with the bid if and only if $y \geq y^{*}$. Otherwise, the bidder is indifferent between continuing the bid and dropping it.

Proof: If $x^{e}>\boldsymbol{b}$, then no shares are tendered and so the bidder is indifferent between continuing and dropping the bid. By Lemma 1 , if $b \geq \max \left\{x^{e}, z\right\}$, then every share is tendered. Hence, the payoff from continuing the bid (ignoring sunk costs) is $R(y)=N y-(N-\kappa) b$. Define

$$
y^{*}= \begin{cases}\bar{y}+1 & \text { if } R(y)<\kappa E[x \mid y] \\ \hat{y} & \text { if } R(\hat{y})=\kappa E[x \mid y] \\ \underline{y} & \text { otherwise }\end{cases}
$$

Since $\frac{d \mathrm{E}\left[x \mid y=y^{\prime}\right]}{d y^{\prime}}<1$ and $\kappa<N, R^{\prime}(y)>\kappa \frac{d \mathrm{E}\left[x \mid y=y^{\prime}\right]}{d y^{\prime}}$. Hence, the bidder continues if and only if $y \geq y^{*}$.

If $z>b \geq x^{e}$, then Lemma 1 implies that the bidder ends up with exactly $K$ shares. His payoff from continuing the bid (ignoring sunk costs) is $R(y)=K y-(K-\kappa) b$. Define $y^{*}$ analogously. Since $\kappa<k<K$, again, the bidder continues if and only if $y \geq y^{*}$.

Lemma 3: In equilibrium, all outstanding shares are tendered to the bidder.

Proof. Since we are considering the case in which the probability of success is positive, Lemma 1 implies that if the stockholders are permitted to tender their shares, the bidder either ends up owning all $N$ of the shares or $K$ of them. So, suppose that the bidder bids $b$, that the set of valuations for which the bidder makes this bid and does not drop it is $Y(b)$, and that the bidder who continues ends up with $K$ shares. That is, the stockholders tender $K-\kappa$ shares. If so, then by Lemma 1 , it must be true that $z>b \geq E[x \mid y \in Y(b)]$. Since we have assumed that $\mu \geq z$, $\mu>\mathrm{E}[x \mid y \in Y(b)]$. For this to be true, there must be some $y \in Y(b)$ such that $\mathrm{E}[x \mid y]<\mu$. Let $y^{\prime}$ be the smallest such $y$. By assumption, $\mu=\mathrm{E}[x \mid y=\mu]$ and $0<\frac{d E[x \mid y]}{d y}<1$. Therefore, $y^{\prime}<\mathrm{E}\left[x \mid y=y^{\prime}\right] \leq \mathrm{E}[x \mid y \in Y(b)] \leq b$. The payoff to a bidder with this valuation is

$$
\begin{aligned}
& K y^{\prime}-(K-\kappa) b+(k-\kappa) p-k \mu-c\left(y^{\prime}\right) \\
= & K\left(y^{\prime}-b\right)+\kappa(b-p)+k(p-\mu)-c\left(y^{\prime}\right) .
\end{aligned}
$$

where $p$ is the market price at which the $k-\kappa$ shares were sold. If $p<b$, then it is optimal to sell no shares, $\kappa=k$. However, this payoff is negative when $\kappa=k$. Hence, our hypothesized situation cannot occur in equilibrium. If $p \geq b$, then the payoff is smaller than the bidder's payoff if he sells all $k$ shares in the market and then drops the bid, a contradiction. Hence, in equilibrium, no bid that leads to the acquisition of $K$ shares in total is made. 
Lemma 4: In equilibrium, if the bidder intends to drop the bid, he sells all of his shares in the market and if he does not intend to drop the bid, he sells none.

Proof: First, we will establish that the stated strategy is a sequential equilibrium, then that it satisfies our refinement, and finally that no other strategy does.

If the bidder intends to drop the bid and holds $\kappa$ shares, his payoff, ignoring sunk costs, is $\kappa E[x \mid y]+(k-\kappa) p^{*}$. Hence, he either sells all shares or none (unless $p^{*}=E[x \mid y]$ ). If he chooses to hold all, the net effect is that he has taken an investment position and, in equilibrium, should have avoided the bidding costs. Thus, except for a set of measure zero, a bidder who intends to drop the bid sells all shares $(\kappa=0)$.

Now, consider the bidder who intends to continue the bid. By hypothesis, $\kappa=k$ and the bid has a positive probability of success in equilibrium. Therefore, $b \geq x^{e}(k, b, \kappa)$. Further, Lemmas 1-3 establish that the computation of $p^{*}$ in the text is correct. Recall that $p^{*}$ is a weighted average of $b$ and $w$, the expected value of a share if the bid is dropped. By Lemma 2, only the high valuation bidders continue and so $x^{e} \geq w$. Since we are only considering the case when the probability of success is strictly between zero and one, $x^{e}>w$. As a result, $b>w$ and so $b>p^{*}$. Therefore, it is optimal for a bidder who intends to continue to not sell any shares $(\kappa=k)$.

To see that these strategies also satisfy our refinement we must show that there is no set of deviators, $Y$, and an optimal response by the stockholders such that the set of valuations for which the deviation is more profitable, $Y^{\prime}$, is equal to $Y$. To see this, note that any bidder who intends to drop the bid receives the same payoff regardless of the stockholders' tendering decisions. Hence, the argument above shows that their profits must decline if they deviate to selling fewer shares.

Now, consider the continuers. Under the proposed strategies, by Lemma 3, all $N-k$ shares are tendered to the bidder. Now, consider a deviation to selling some shares. If the stockholders' optimal response to a proposed set of deviators is tender all of the shares that the bidder does not own, then there are no valuations for which the profits from the deviation exceed the profits from selling no shares. The reason is that the only effect of the deviation is that any shares sold in the market are repurchased for more than they were sold for. If the stockholders' optimal response is to tender fewer shares, the bidder must acquire none. This is true because, by Lemma 3, we must have $b>z$. By Lemma 1 , this means that either the bidder ends up with every share or none. If the bidder ends up with none, he has essentially taken an investment position and would have made more profits by not bidding. Hence, the proposed strategies satisfy our refinement.

Lastly, we must show that there is no other equilibrium outcome. Suppose not. Then either the manipulator holds some shares or the serious bidder sells some. Above, we showed that the former is not even a sequential equilibrium. So consider the second possibility and let the number of shares the serious bidder retains in equilibrium be $\kappa$. By Lemma 3, the serious bidder acquires sil outstanding shares, $b \geq x^{e}(k, b, \kappa)$. Consider a deviation to selling no shares when the market is open. Given that a serious bidder receives all outstanding shares, the deviation is profitable for all of the serious bidders in the candidate equilibrium because $b>p^{*}$ and they continue to receive all outstanding shares. Hence, if $Y^{\prime}$, the set of valuations for which the deviation is more 
profitable, differs from the set of serious bidders, it is because some low valuation bidders switched to continuing the bid. Therefore, the expectation of $x$ conditional on $Y^{\prime}$ must be smaller than $x^{e}(k, b, \kappa)$. Since $b \geq \max \left\{x^{e}, z\right\}$, we see that the stockholders' optimal response to the deviation is to tender all outstanding shares as conjectured. This breaks the proposed equilibrium.

Lemma 5: In equilibrium the only initial position is $\bar{k}$ and the only bid made with positive probability is $\mathrm{E}\left[x \mid y \geq y_{c}\right]$.

Proof: Suppose that more than one bid is made with positive probability in equilibrium. Let $b_{i}$ for $i \in I$ denote the bids, ${ }^{2}$ where $b_{i}>b_{j}$ for $i<j$. Let the associated initial holdings be $k_{i}$ for $i \in I$. Recall that the manipulators only make bids that serious bidders make so that we must have serious bidders making every bid. A serious bidder's payoff from $\left(k_{i}, b_{i}\right)$ is $N y-\left(N-k_{i}\right) b_{i}-k_{i} \mu-c(y)$. Independent of the bidder's valuation, $y$, this is decreasing in $b_{i}$ for a fixed $k_{i}$ and is increasing in $k_{i}$ for a fixed $b_{i}$. Hence, if the serious bidders are to make every bid, they must be indifferent between all $\left(k_{i}, b_{i}\right)$ pairs and we must have $\bar{k} \geq k_{i}>k_{j}$ for $i<j$. That is, for the set of hypothesized equilibrium pairs of initial positions and bids, smaller initial positions must be associated with smaller bids.

Let the set of serious bidders who bid $b_{i}$ be $Y\left(b_{i}\right)$ for $i \in I$ and let $b^{\prime}=\sum_{i \in I} b_{i} \operatorname{Pr}\left\{y \in Y\left(b_{i}\right)\right\}$. Consider the deviation to acquiring an initial position of $\bar{k}$ shares, bidding $b^{\prime}$, selling no shares in the market and not dropping the bid. Let $Y^{\prime}$ be the set of bidders who deviate to this strategy given that the stockholders respond to this deviation by tendering all shares. We must show that (1) the deviation produces an off-the-equilibrium path action, (2) given the inference that $y \in Y^{\prime}$, the stockholders' optimal reply is to tender all shares to the bidder.

First, note that this the deviation produces an off-the-equilibrium path action. The reason is that there can be no $i$ such that $\left(k_{i}, b_{i}\right)=\left(\bar{k}, b^{\prime}\right)$ because $k_{i}$ would be the largest initial position and it would be associated with a bigger bid, $b_{i}>b^{\prime}$ by construction. Next, note that for a specified set of initial positions, bids and market prices, the serious bidder's payoff is monotonically increasing in $y$. This means that $U_{i \in I} Y\left(b_{i}\right)$ must be an interval which includes $\bar{y}$. Further, because the deviation is to a lower bid and a larger initial position, all of these types prefer the deviation. Thus, giv'sn that the stockholders tender all shares, $Y^{\prime}$ contains $\cup_{i \in I} Y\left(b_{i}\right)$. If these sets are not equal, then $Y^{\prime}$ includes some additional lower valuations. Next, note that, by hypothesis, the bids succeed with positive probability which, by Lemma 1 , implies that $b_{i} \geq E\left[x \mid y \in Y\left(b_{i}\right)\right]$. Hence, $b^{\prime} \geq \mathrm{E}\left[x \mid y \in \cup_{i \in I} Y\left(\dot{b}_{i}\right)\right]$. Therefore, $b^{\prime} \geq \mathrm{E}\left[x \mid y \in Y^{\prime}\right]$. This means that the stockholders' best reply is to tender all shares to bidders who choose $\left(\bar{k}, b^{\prime}\right)$. This means that our hypothesis is false. There: is no equilibrium with more than one bid.

Next, we show that the initial position is $\bar{k}$. First, note that the investor's payoff is strictly increasing in their initial position and so they will choose to acquire $\bar{k}$ in any equilibrium. Also, recall that a necessary condition for the manipulators to make positive profits is that they emulate the serious bidders. Thus, if we are to have an equilibrium with less than $\bar{k}$ shares acquired as an initial position, we must have some serious bidders choosing it. Also, since we have shown above

2 Note that $I$ can be a finite set, countably infinite or an interval. 
that there is only one bid made in equilibrium, we know that there is only one initial position taken in equilibrium. So, suppose that we have an equilibrium in which the serious bidders take an initial position of $k<\bar{k}$ shares, and bid $b_{1}$. Let the set of valuations for which the bidder is serious be $Y_{1}$, an interval that includes $\bar{y}$. Since there is only one bid in equilibrium, we can compute the critical values and the equilibrium buying price as functions of $k$ and $b_{1}$.

Consider a deviation to an initial position of $\bar{k}$ shares, the same bid, selling no shares in the market and not dropping the bid. Since there was only one initial position taken by those who bid, this deviation produces an off-the-equilibrium path action. Suppose that the set of bidders who prefer the deviation is $Y^{\prime}$ and that the stockholders respond by tendering all of their shares. Since the initial position is larger and the stockholders still tender all shares, every $y \in Y_{1}$ prefers the deviation. Thus, $Y^{\prime} \subseteq Y_{1}$. If it is larger then some lower valuation bidders are also deviating. This means that $b_{1} \geq E\left[x \mid y \in Y^{\prime}\right]$ and so the stockholders will tender every share. This means that the candidate equilibrium does not satisfy our refinement. As a result, $\bar{k}$ shares is the initial position acquired in any equilibrium.

Finally, we must show that the single bid made is $\mathrm{E}\left[x \mid y \geq y_{c}\right]$ where $y_{c}$ is calculated as in the text. In particular, this means that it is calculated given that the initial position is $\bar{k}$. Since we know that only one bid is made in equilibrium and that the initial position is $\bar{k}$, we can compute the critical values and the equilibrium buying prices as a function of the bid in the manner described in the text. Thus, for a given bid say $b_{1}$, we know that the set of serious bidders is $y \geq y_{c}\left(b_{1}\right)$. Since the bid is to succeed with positive probability, we also know that $b_{1} \geq E\left[x \mid y \geq y_{c}\left(b_{1}\right)\right]$. To see that the equilibrium bid satisfies $b=\mathrm{E}\left[x \mid y \geq y_{c}(b)\right]$, suppose not. Then, $b_{1}>\mathrm{E}\left[x \mid y \geq y_{c}\left(b_{1}\right)\right]$. Consider a deviation with the same initial position, $b^{\prime}=b_{1}-\epsilon$ for $\epsilon>0$, selling no shares in the market and not dropping the bid. Let $Y^{\prime}$ be the set of bidders who deviate to this strategy and assume that the stockholders tender every share. From this, we can compute the set of valuations for which the deviation is preferred. Since the bid is smaller and the number of shares tendered is the same, every serious bidder in the candidate equilibrium prefers the deviation. Hence $Y^{\prime}$ contains $y \geq y_{c}\left(b_{1}\right)$. If the sets differ, then some additional, lower valuations are deviating to this strategy too. In either case, the continuity of the conditional expectation in $y_{c}$ implies that $b^{\prime} \geq \mathrm{E}\left[x \mid y \in Y^{\prime}\right]$ for $\epsilon$ sufficiently small. Hence, the stockholders will tender every share and so we have a contradiction. Therefore, the single bid made in equilibrium satisfies $b=\mathrm{E}\left[x \mid y \geq y_{c}(b)\right]$.

At this point, we should note that the above Lemmas imply that the critical values and the equilibrium buying price have been calculated correctly in the text. Also, we note that the probability of the bid being continued and succeeding is one for an $\mathrm{i}$-form equilibrium. Thus, the case when the probability of success is one is handled in the proof that an i-form exists and is unique for certain parameter values.

Theorem 1: There is a unique equilibrium and, depending on the parameter values, it is either an i-form, an im-form or an m-form equilibrium.

Proof: (1) an i-form equilibrium: In the $\mathrm{i}$-form, there is no manipulation. This means that $p^{*}=b$ and that $\forall y \in[\underline{y}, \bar{y}], \max \left\{\pi^{c}(y), \pi^{i}(y), 0\right\}>\pi^{m}(y)$. The former follows because the probability that the bid is not dropped is one and the latter follows from the requirement that in an i-form, 
the upper envelope of Ted's payoffs must not include $\pi^{m}$.

Thus, we must show that there are parameter values for which we get an i-form equilibrium and then that for those parameters, the equilibrium is unique. To do the former, we begin by describing the necessary conditions so that $\pi^{m}$ is not in the upper envelope of payoffs. Next, we show that there are serious bidders and inactive bidders. This will be seen to be sufficient to ensure that an $i$-form equilibrium exists and so our last task will be to prove that it is unique.

The parameter conditions that ensure that $\pi^{m}$ is not in the upper envelope are derived in three steps. First, we show that $\mu<y_{c}$. To see this, suppose not. Then $\pi^{i}(\mu) \leq \pi^{c}(\mu)$. Substituting and rearranging shows this to be equivalent to $0 \leq(N-\bar{k})(\mu-b)-c(\mu)$. Since $b \geq \mu$, we have a contradiction. Hence, $\mu<y_{c}$. Next, we appeal to the monotonicity of the payoff functions in $y$ and their relative slopes to show that a necessary and sufficient condition for $\max \left\{\pi^{c}(y), \pi^{i}(y), 0\right\}>$ $\pi^{m}(y) \forall y \in[\underline{y}, \bar{y}]$ is that $\pi^{i}(\mu) \geq \pi^{m}(\mu)$. Recall that $\pi^{i}(y)=(\mathrm{E}[x \mid y]-\mu) \bar{k}$. Since $\mathrm{E}[x \mid y=\mu]=\mu$ this means that $\pi^{i}(\mu)=0$. Finally, recall that, in the text, we showed that

$$
\frac{\partial \pi^{c}(y)}{\partial y}>\frac{\partial \pi^{i}(y)}{\partial y}>\frac{\partial \pi^{m}(y)}{\partial y}
$$

Combining these two facts, we see that the necessary and sufficient condition for $\pi^{m}$ to not be part of the upper envelope is that $\pi^{i}(\mu) \geq \pi^{m}(\mu)$, which is equivalent to $\pi^{m}(\mu) \leq 0$. Since $\pi^{m}(\mu)=\left(p^{*}-\mu\right) \bar{k}-c(\mu)$, substituting for $p^{*}$, which equals the bid, the condition becomes

$$
\mu+\frac{c(\mu)}{\bar{k}}>\mathrm{E}\left[x \mid y \geq y_{c}\right] \text {. }
$$

Hence, if (A1) holds, $\pi^{m}$ is not part of the upper envelope.

Now, we show that there are inactive bidders and serious bidders. The former are those valuations for which the payoffs from manipulating, investing and being a serious bidder are all negative. Again, because of the reiative slopes, the set of inactive bidders when no manipulation occurs is the set of valuations for which $\pi^{i}(y)<0$. Above, we showed that $\pi^{i}(\mu)=0$ so that monotonicity implies that the set of inactive bidders is $[\underline{y}, \mu)$. By assumption, $\underline{y}<\mu$ so there are inactive bidders. To show ihat there are serious bidders, we must show that $y_{c}<\bar{y}$ where $y_{c}$ is defined by $\pi^{i}\left(y_{c}\right)=\pi^{c}\left(y_{c}\right)$. Again, by monotonicity, this follows if $\pi^{i}(\bar{y})<\pi^{c}(\bar{y})$. To show this, suppose not. Then $\pi^{c}(\ddot{y})=N \bar{y}-(N-\bar{k}) b-c(\bar{y})-\bar{k} \mu$ where $b=\mathrm{E}[x \mid y \geq \bar{y}] \equiv \mathrm{E}[x \mid y=\bar{y}]$. By hypothesis, this muist less than or equal to $\pi^{i}(\bar{y})$ which is equal to $(\mathrm{E}[x \mid y=\bar{y}]-\mu) \bar{k}$. Setting $\pi^{c}(\bar{y}) \leq \pi^{i}(\bar{y})$ and rearranging yields

$$
N(\bar{y}-\mathrm{E}[x \mid y=\bar{y}])-c(\bar{y}) \leq 0 .
$$

However, one of our maintained assumptions is that this is positive. Hence, we have a contradiction and conclude that $y_{c}<\bar{y}$ and that the set of serious bidders is $y \in\left[y_{c}, \bar{y}\right]$.

What we have shown to this point is that the only additional restriction on the parameter values (other than those restrictions maintained throughout the analysis) that is needed to generate an $\mathrm{i}$-form equilibrium is (A1). All that is left for now is to show that if we have an $\mathrm{i}$-form then 
it is unique. To see this, note that in an $\mathrm{i}$-form, there is no manipulation and so $\boldsymbol{p}^{*}=b$. Further, we showed in Lemma $5^{3}$ that in any equilibrium there is one initial position, $\bar{k}$, and one bid made which satisfies $b=\mathrm{E}\left[x \mid y \geq y_{c}(b)\right]$. Hence, to show uniqueness, we must show that there is only one bid that satisfies this equation and that the critical values are uniquely defined. The former is straightforward and the latter is a simple consequence of the monotonicity of the payoffs and the fact that

$$
\frac{\partial \pi^{c}(y)}{\partial y}>\frac{\partial \pi^{i}(y)}{\partial y}>\frac{\partial \pi^{m}(y)}{\partial y}
$$

Thus, we have provided the parameter condition (A1) that generates an $\mathrm{i}$-form equilibrium and have shown that if there is an $\mathrm{i}$-form equilibrium, then there is only one $\mathrm{i}$-form equilibrium.

(2) an im-form equilibrium: In this form of equilibrium, each activity must be optimal for some set of valuations. By monotonicity and the relative slopes of the payoffs, we see that the set of inactive bidders is $\left[\underline{y}, y_{m}\right)$, the set of manipulators is $\left(y_{m}, y_{i}\right)$, the set of investors is $\left[y_{i}, y_{c}\right)$ and the set of serious bidders is $\left[y_{c}, \bar{y}\right]$. In equilibrium, each of the critical values is found by determining the valuation which is indifferent between the two relevant activities. We will find it useful to define these critical values as functions of the buying price in order to more readily prove existence and uniqueness for this equilibrium form.

We proceed as follows. First, we derive the parameter conditions necessary to correctly order the critical values. Next, we show that the critical values are uniquely defined for each buying price in the relevant range. From this, we are able to show that an im-form equilibrium exists. Finally, we show that for this set of parameter restrictions, the im-form equilibrium is unique.

Since $y_{c}$ is defined by indifference between investing and making a serious bid, it is defined by the same condition as in an i-form equilibrium and so our demonstration that $y_{c}<\bar{y}$ for an $\mathrm{i}$-form carries over exactly. Next, we need to show that $y_{i}<y_{c}$. This is equivalent to showing that $\pi^{i}\left(y_{i}\right)>\pi^{c}\left(y_{i}\right){ }^{4}$ Substituting gives

$$
\bar{k} \mathrm{E}\left[x \mid y=y_{i}\right]>N y_{i}-(N-\bar{k}) \mathrm{E}\left[x \mid y \geq y_{c}\right]-c\left(y_{i}\right)
$$

If it holds, we will have an im-form. If it does not, then we will have an $\mathrm{m}$-form equilibrium. Next, we need to show that $y_{i}>\mu$. Because of the relative slopes, this will be true if $\pi^{m}(\mu)>0$. Recall that this is exactly the reverse of the necessary condition for an $\mathrm{i}$-form to occur. Hence, if (A1) is violated, then $\pi^{m}(\mu)>0$ and so $y_{i}>\mu$. To see that $y_{m}<\mu$, note that $\pi^{m}(\mu)>0$. Since $\pi^{m}$ is increasing and continuols in $y$, this implies that $y_{m}$, which satisfies $\pi^{m}\left(y_{m}\right)=0$ must be less than $\mu$. Finally, we need ;o show that $\underline{y}<y_{m}$. So, suppose not. Then since $\hat{\phi}<\phi$, we have that $p<\mathrm{E}\left[x \mid y \notin\left[y_{i}, y_{c}\right)\right]$. Since $\pi^{i}(\mu)=0, y_{i}>\mu$ which implies that $\mathrm{E}\left[x \mid y \in\left[y_{i}, y_{c}\right)\right]>\mu$. This means that $\mathrm{E}\left[x \mid y \notin\left[y_{i}, y_{c}\right)\right]<\mu$ which implies that $\vec{k} p-c(y)<\bar{k} \mu$ for all $y$. Therefore, if an im-form exists, then $\underline{y}<y_{m}$.

3 The careful reader will recall that that Lemma was proved under the assumption that the bid succeeded with positive probability, less than one. However, a quick look at that proof will show that our arguments readily extend to the case when the probability of success is one.

4 The reader may wish to refer to figure 2. 
This lengthy analysis shows that the critical values will be correctly ordered in an im-form if (A1) does not hold and (A2) does. Next, we show that these critical values can be defined as functions of the buying price and that existence of equilibrium is equivalent to finding a buying price that is a fixed point for (A3) defined below.

Recall that $y_{m}$ is the valuation for which the bidder is indifferent between being inactive and manipulating- $0=\pi^{m}\left(y_{m}\right)$. Using the definition of $\pi^{m}$, this is equivalent to $0=\bar{k}(p-\mu)-c\left(y_{m}\right)$. This equation implicitly defines $y_{m}$ as a function of $p$. Next, recall that $y_{i}$ is defined by $\pi^{m}\left(y_{i}\right)=$ $\pi^{i}\left(y_{i}\right)$. Rewriting, $\bar{k} p-c\left(y_{i}\right)=\mathrm{E}\left[x \mid y=y_{i}\right] \bar{k}$, which implicitly defines $y_{i}$ as a function of $p$. Lastly, $y_{c}$ is defined by $\pi^{i}\left(y_{c}\right)=\pi^{c}\left(y_{c}\right)$. Rewriting, $E\left[x \mid y=y_{c}\right] \bar{k}=N y_{c}-(N-\bar{k}) b-c\left(y_{c}\right)$. In an im-form, we see that $y_{c}$ is independent of $p$ because the buying price does not affect either the payoff from investing or the payoff from making a serious bid.. However, when we consider an $m$-form below, $y_{c}$ will be defined by indifference between manipulating and making a serious bid. Hence, in that form $y_{c}$ will be a function of the buying price. To avoid unnecessary repetition, we will write $y_{c}$ as a function of the buying price here and keep in mind that changes in $p$ have no effect on $y_{c}$.

Now, recall that $p^{*}=\hat{\phi} \mathrm{E}\left[x \mid y \geq y_{c}\right]+(1-\hat{\phi}) \mathrm{E}\left[x \mid y \in\left[y_{m}, y_{i}\right)\right]$, where use is being made of Lemma 5. Thus, we can characterize equilibrium as a fixed point of this function. Substituting for $\hat{\phi}, \phi$ and $b$, the right hand side is $P\left(y_{m}, y_{i}, y_{c}\right)$. Thus, equilibrium is characterized by $p^{*}=$ $P\left(y_{m}\left(p^{*}\right), y_{i}\left(p^{*}\right), y_{c}\left(p^{*}\right)\right)$. Writing $P$ explicitly,

$$
\begin{aligned}
P= & \frac{\gamma\left(1-F\left(y_{c}\right)+F\left(y_{i}\right)-F\left(y_{m}\right)\right)}{\gamma\left(1-F\left(y_{c}\right)+F\left(y_{i}\right)-F\left(y_{m}\right)\right)+\bar{k}\left(F\left(y_{i}\right)-F\left(y_{m}\right)\right)} \mathrm{E}\left[x \mid y \geq y_{c}, y \in\left[y_{m}, y_{i}\right)\right] \\
& +\frac{\bar{k}\left(F\left(y_{i}\right)-F\left(y_{m}\right)\right)}{\gamma\left(1-F\left(y_{c}\right)+F\left(y_{i}\right)-F\left(y_{m}\right)\right)+\bar{k}\left(F\left(y_{i}\right)-F\left(y_{m}\right)\right)} \mathrm{E}\left[x \mid y \in\left[y_{m}, y_{i}\right)\right] \\
= & \frac{\gamma}{\Delta}\left[\int_{y_{c}}^{\bar{y}} \mathrm{E}[x \mid y] f(y) d y+\int_{y_{m}}^{y_{i}} \mathrm{E}[x \mid y] f(y) d y\right]+\frac{\bar{k}}{\Delta} \int_{y_{m}}^{y_{i}} \mathrm{E}[x \mid y] f(y) d y,
\end{aligned}
$$

where $\Delta=\gamma\left(1-F\left(y_{c}\right)+F\left(y_{i}\right)-F\left(y_{m}\right)\right)+\bar{k}\left(F\left(y_{i}\right)-F\left(y_{m}\right)\right)$.

Since we seek a buying price that satisfies this equation, we will find it useful to abuse notation and write $P\left(y_{m}(p), y_{i}(p), y_{c}(p)\right)$ as $P(p)$. Thus, to show existence, notice that $P$ is continuous in $p$. Next observe that at $p=\mu$, there is no, valuation for which the bidder manipulates. Therefore $P(\mu)=b>\mu$. Next, observe that at $p=b$, there is a measurable set of valuations for which the bidder manipulates and so $P(b)<b$. Hence, there exists a $p^{*}$ such that $p^{*}=P\left(p^{*}\right)$ which implies that when (A1) does not hold and (A2) does, an im-form equilibrium exists.

Consequently, all that is left is to show that under these parameter restrictions, there is only one im-form equilibrium. Again, from above, this is equivalent to showing that there is only one solution to $p^{*}=P\left(p^{*}\right)$. To see this, differentiate (A3) with respect to $p$ to obtain

$$
\begin{aligned}
\frac{d P}{d p}= & \frac{1}{\Delta}\left[-\gamma f\left(y_{c}\right)\left[\mathrm{E}\left[x \mid y_{c}\right]-P\right] \frac{d y_{c}}{d p}+(\gamma+\bar{k}) f\left(y_{i}\right)\left[\mathrm{E}\left[x \mid y_{i}\right]-P\right] \frac{d y_{i}}{d p}\right. \\
& \left.-(\gamma+\bar{k}) f\left(y_{m}\right)\left[\mathrm{E}\left[x \mid y_{m}\right]-P\right] \frac{d y_{m}}{d p}\right] .
\end{aligned}
$$


As we noted above, in an im-form equilibrium, $y_{c}$ is not a function of $p$ so the first term of (A4) is zero. Using the defining equations for $y_{i}$ and $y_{m}$, differentiation gives $\frac{d y_{i}}{d p}>0$ and $\frac{d y_{m}}{d p}<0$. Thus, we need the relationship between $P$ and the conditional expectations to sign (A4). Evaluating at a solution and using the definition of $y_{i}$ we see that $p^{*}>\mathrm{E}\left[x \mid y=y_{i}\right]$. Further, since $\mathrm{E}[x \mid y]$ is increasing in $y$, we have $p^{*}>\mathrm{E}\left[x \mid y=y_{m}\right]$. Substituting all of this into (A4), we see that $\frac{d P\left(p^{*}\right)}{d p}<0$ at any equilibrium. Thus, the equilibrium is unique.

(3) an $m$-form equilibrium: In an $m$-form equilibrium, there is no $y$ such that taking an investment position is optimal. That is, $\forall y \in[\underline{y}, \bar{y}], \quad \max \left\{\pi^{m}(y), \pi^{c}(y), 0\right\} \geq \pi^{i}(y)$. From the discussion of the im-form, we know that the parameter conditions for this are that neither (A1) nor (A2) hold. Given this, we must show that the two critical values satisfy $\underline{y}<y_{m}<\mu<y_{c}<\bar{y}$. The im-form analysis carries over to tell us that $\underline{y}<y_{m}<\mu$ because the condition that defines $y_{m}$ in the im-form is the same as in the $\mathrm{m}$-form. In the $\mathrm{m}$-form, $y_{c}$ is defined by $\bar{k} p=N y_{c}-(N-\bar{k}) \mathrm{E}\left[x \mid y \geq y_{c}\right]$.

To see that the remaining inequalities hold, observe that, in an $\mathrm{m}$-form equilibrium, the buying price must be strictly between $\mu$ and $b$. Since $\pi^{c}(\mu)=N \mu-(N-\bar{k}) b-c(\mu)$ and $\pi^{m}(\mu)=\bar{k} p-c(\mu)$, we see that $\pi^{c}(\mu)<\pi^{m}(\mu)$. Combined with our results on the relative slopes of these functions, this means that $\mu<y_{c}$. Next, since $p<b, \pi^{c}(\bar{y})>\pi^{m}(\bar{y})$, and so $y_{c}<\bar{y}$.

To complete the proofs of uniqueness and existence, we can follow the same reasoning as in the im-form. Define the function $P$ as above noting that it is now a function of $y_{m}$ and $y_{c}$. Analogous computations then complete the proof.

(4) equilibria are mutually exclusive: We have shown that if (A1) holds, we have an i-form and that in order to have either an im-form or an $\mathrm{m}$-form, (A1) must not hold. Hence, to show mutual exclusivity, we need only show that we cannot have both an im-form and an $m$-form simultaneously. The mutual exclusivity of the im-form and the $m$-form is straightforward. Simply compute the critical values, the bid, and the equilibrium buying price as if we have an im-form equilibrium. Check (A2). If it is satisfied, we have an im-form and we know that we cannot have an $\mathrm{m}$-form. If (A2) is not satisfied, recompute to obtdin the $\mathrm{m}$-form. 


\section{References}

Admati, A., and P. Pfleiderer, "A Theory of Intraday Patterns: Volume and Price Variability," Review of Financial Studues, Spring 1988, pp. 3-40.

Ausubel, L., "Insider Trading in a Rational Expectations Economy," Northwestern University working paper, April, 1989.

Bagnoli, M., and B. L. Lipman, "Successful Takeovers without Exclusion," Review of Financial Studues, Spring 1988, pp. 89-110.

Benabou, R., and Guy Laroque, "Using Privileged Information to Manipulate Markets: Insiders, Gurus and Credibility," Massachusetts Institute of Technology working paper, February, 1989.

Fishman, M., and K. Hagerty, "Insider Trading and the Efficiency of Stock Prices," Northwestern University working paper, March, 1989.

Glosten, L., and P. Milgrom, "Bid, Ask, and Transaction Prices in a Specialist Market with Heterogeneously Informed Traders," Journal of Financial Economics, June, 1985, pp. 71-110.

Grossman, S., and M. Perry, "Perfect Sequential Equilibrium," Journal of Economic Theory, June 1986, pp. 97-119.

Kyle, A., "Informed Speculation with Imperfect Information," Review of Economic Studies, July, 1989, pp. 317-355.

Mergers and Acquisitions Almanac and Index, 1985, pp. 43,44 and 1986, pp. 54, 55.

Mirman, L., and L. Samuelson, "Information and Equilibrium with Inside Traders," Pennsylvania State University working paper, February, 1988. 


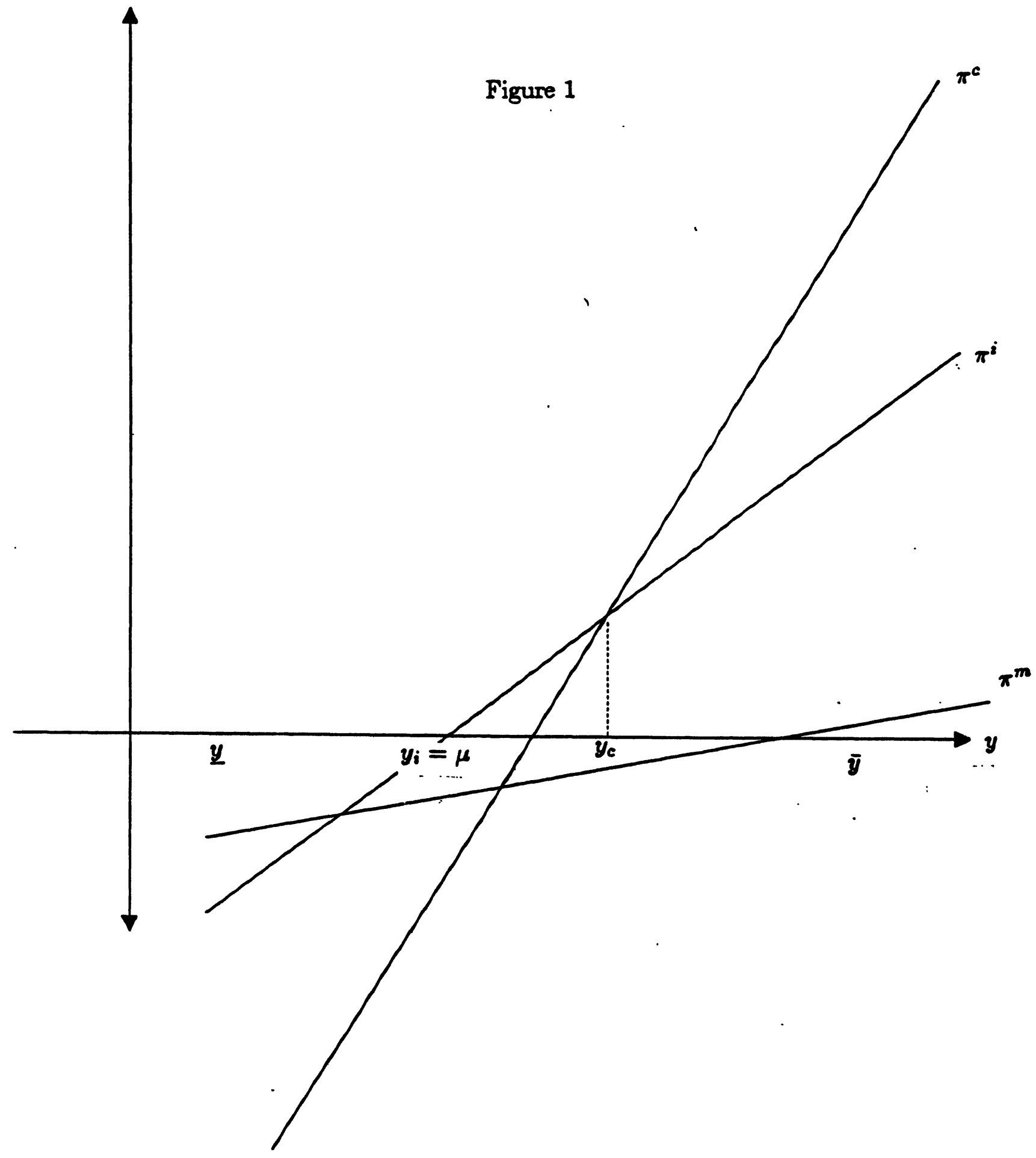




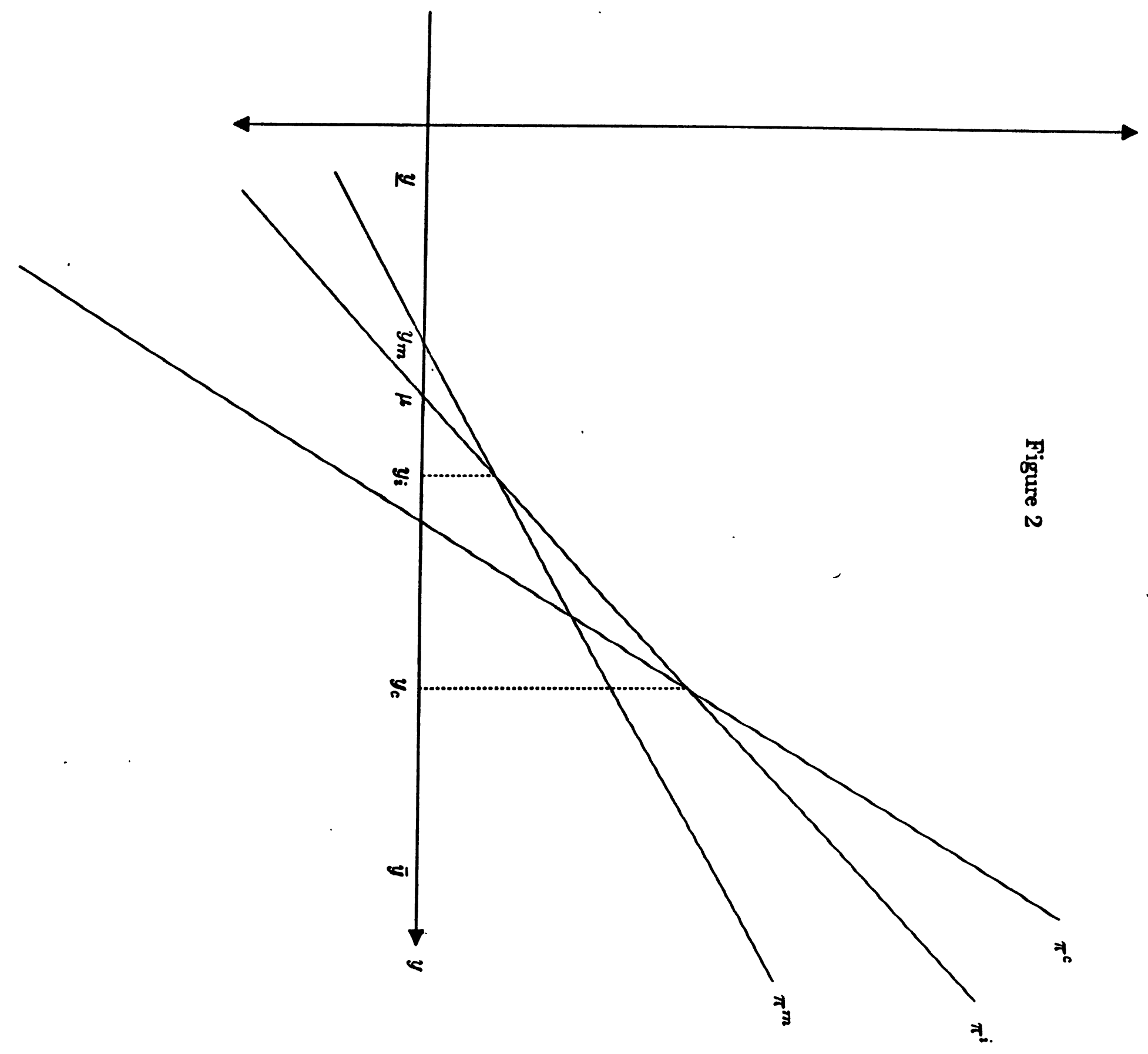




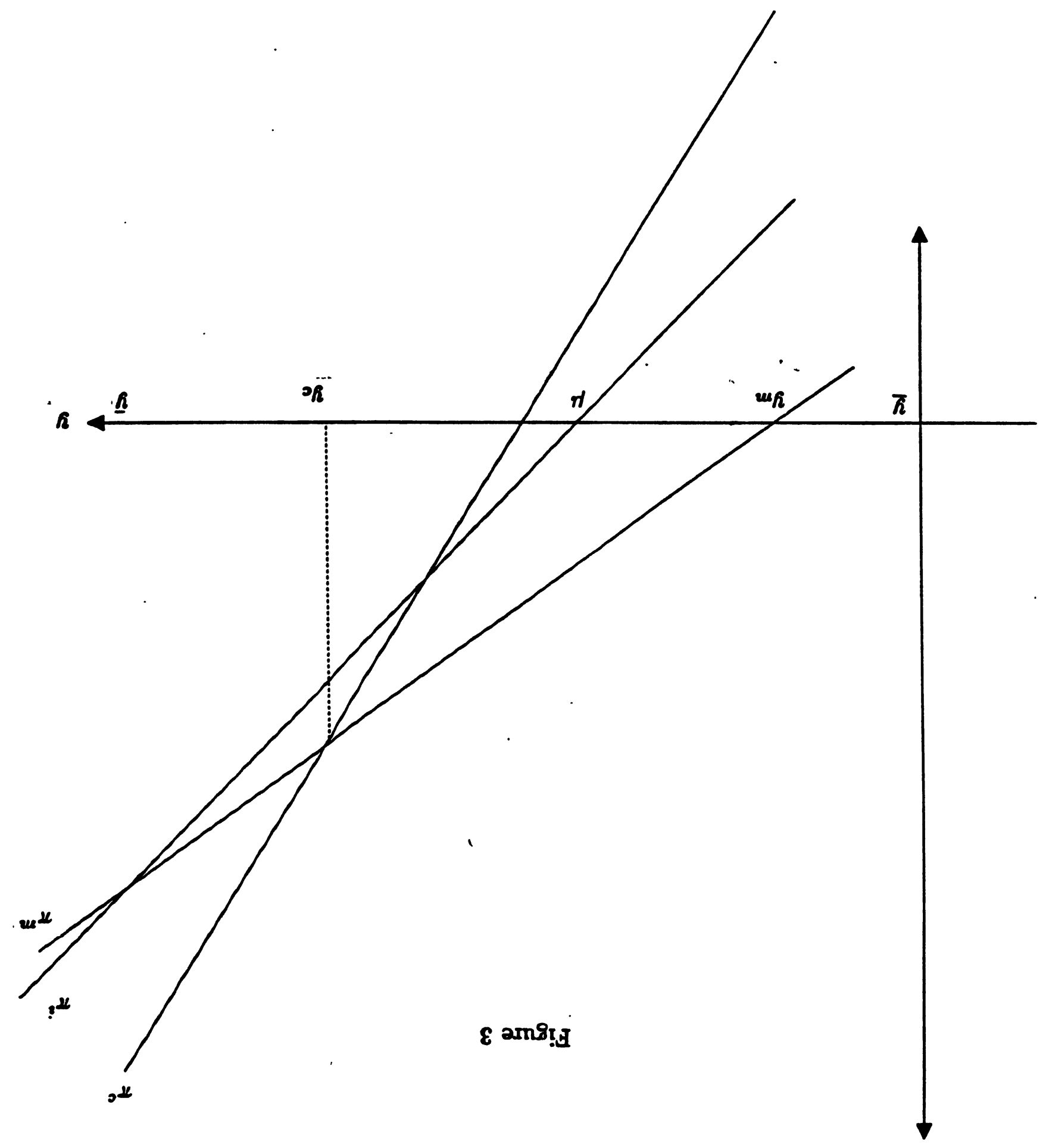




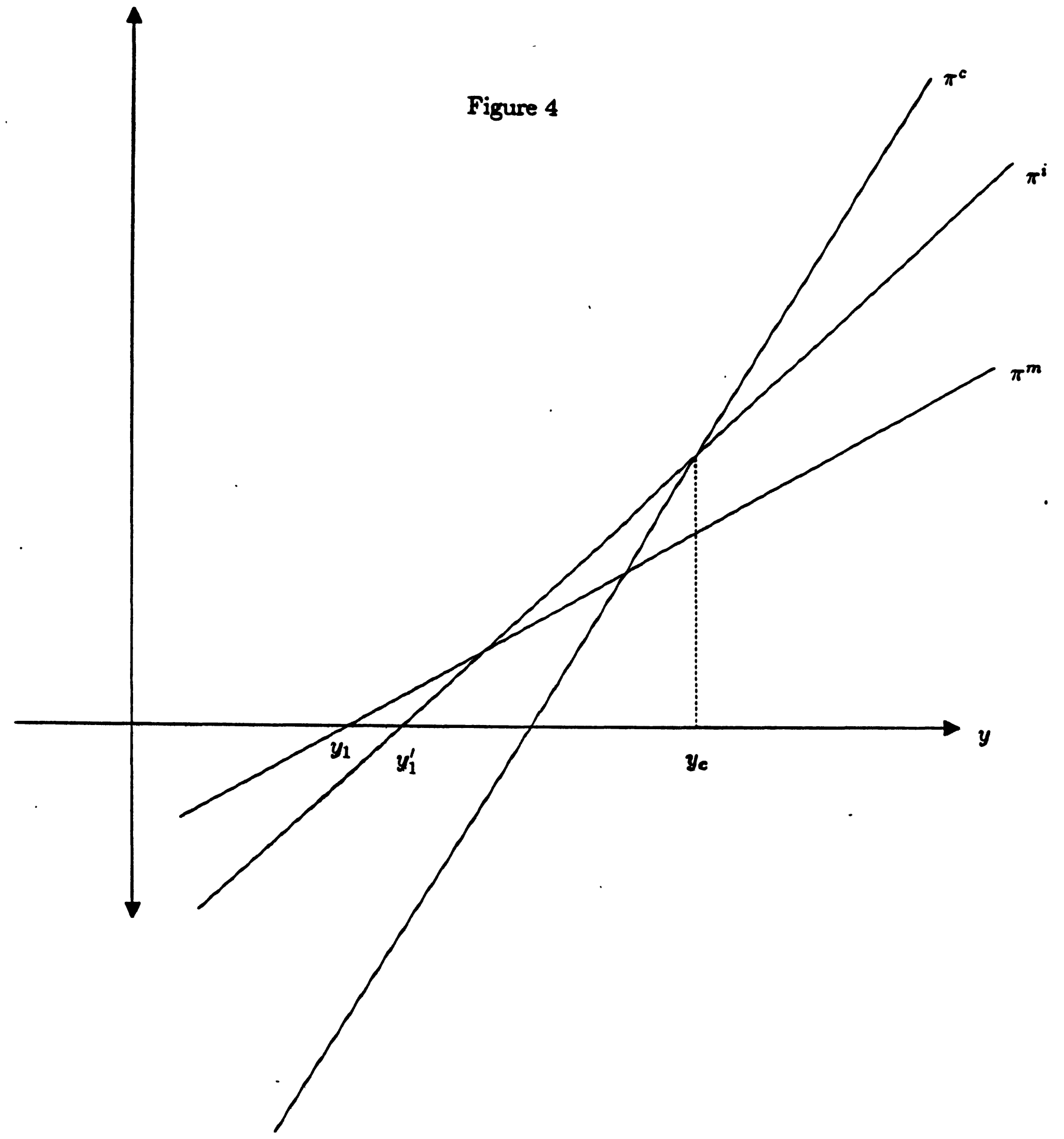




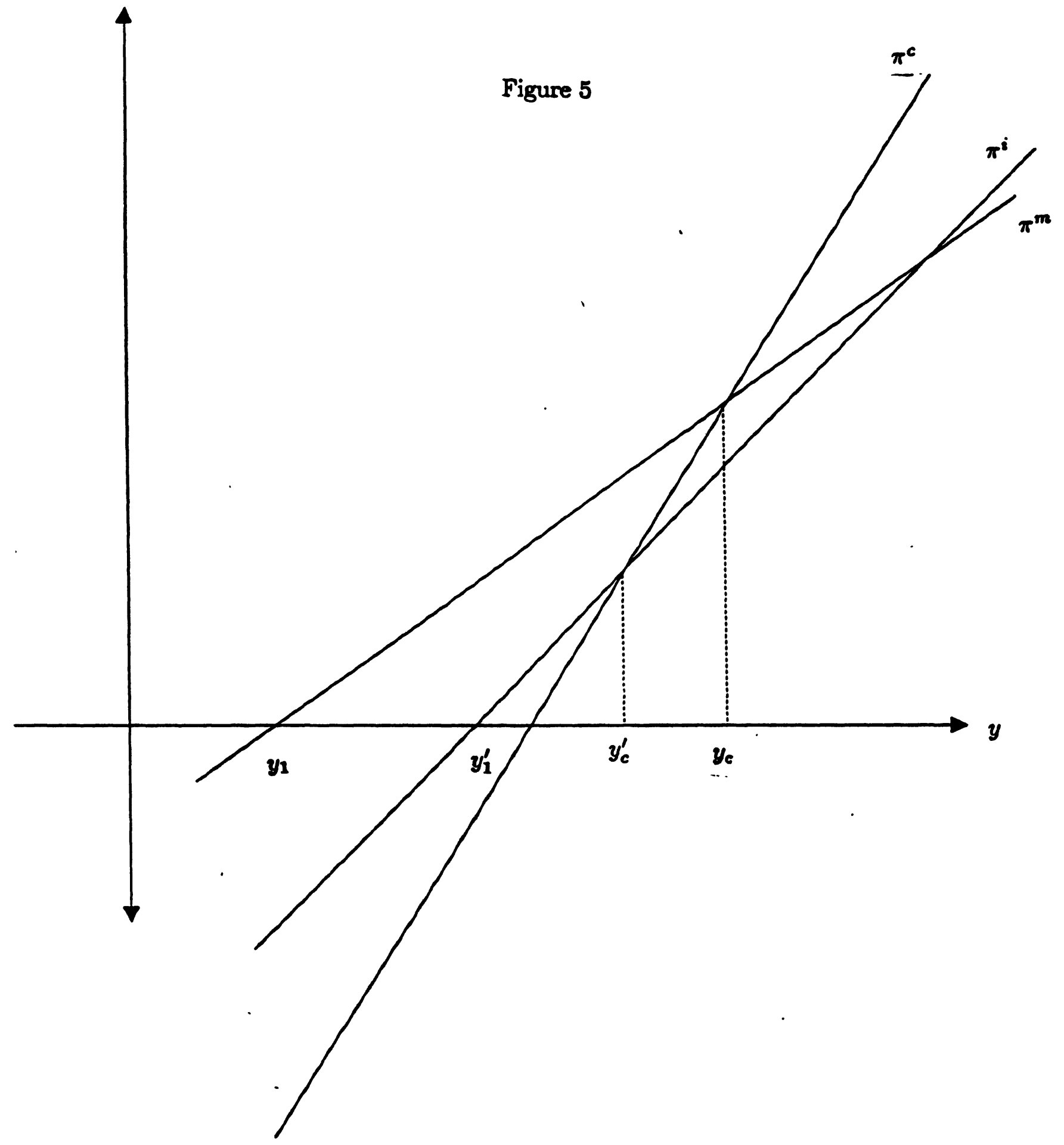





\section{Recent CREST Working Papers}

89-01: Mark Bagnoli, Severin Borenstein, "Carrot and Yardstick Regulation: Enhancing Market Performance with Output Prizes," October, 1988.

89-02: Ted Bergstrom, Jeffrey K. MacKie-Mason, "Some Simple Analytics of Peak-Load Pricing," October, 1988.

89-03: Ken Binmore, "Social Contract I: Harsanyi and Rawls," June, 1988.

89-04: Ken Binmore, "Social Contract II: Gauthier and Nash," June, 1988.

89-05: Ken Binmore, "Social Contract III: Evolution and Utilitarianism," June, 1988.

89-06: Ken Binmore, Adam Brandenburger, "Common Knowledge and Game Theory," July, 1989.

89-07: Jeffrey A. Miron, "A Cross Country Comparison of Seasonal Cycles and Business Cycles," November, 1988.

89-08: Jeffrey A. Miron, "The Founding of the Fed and the Destabilization of the Post-1914 Economy," August, 1988.

89-09: Gérard Gaudet, Stephen W. Salant, "The Profitability of Exogenous Output Contractions: A Comparative-Static Analysis with Application to Strikes, Mergers and Export Subsidies," July, 1988.

89-10: Gérard Gaudet, Stephen W. Salant, "Uniqueness of Cournot Equilibrium: New Results from Old Methods," August, 1988.

89-11: Hal R. Varian, "Goodness-of-fit in Demand Analysis," September, 1988.

89-12: Michelle J. White, "Legal Complexity," October, 1988.

89-13: Michelle J. White, "An Empirical Test of the Efficiency of Liability Rules in Accident Law," November, 1988.

89-14: Carl P. Simon, "Some Fine-Tuning for Dominant Diagonal Matrices," July, 1988.

89-15: Ken Binmore, Peter Morgan, "Do People Exploit Their Bargaining Power? An Experimental Study," January, 1989.

89-16: James A. Levinsohn, Jeffrey K. MacKie-Mason, "A Simple, Consistent Estimator for Disturbance Components in Financial Models," April 25, 1989.

89-17: Hal R. Varian, "Sequential Provision of Public Goods," July, 1989.

89-18: Hal R. Varian, "Monitoring Agents with Other Agents," June, 1989.

89-19: Robert C. Feenstra, James A. Levinsohn, "Distance, Demand, and Oligopoly Pricing," July 17, 1989.

89-20: Mark Bagnoli, Shaul Ben-David, Michael McKee, "Voluntary Provision of Public Goods," August, 1989.

89-21: N. Gregory Mankiw, David Romer, Matthew D. Shapiro, "Stock Market Forecastability and Volatility: A Statistical Appraisal," August, 1989.

89-22: Arthur J. Robson, "Efficiency in Evolutionary Games: Darwin, Nash and the Secret Ilandshake," 1989.

89-23: Mark Bagnoli, Ted Bergstrom, "Log-Concave Probability and Its Applications," September 7, 1989.

89-24: Gérard Gaudet, Stephen W. Salant, "Towards a Theory of Horizontal Mergers," July, 1989.

89-25 (evolved from 87-35): Stephen W. Salant, Eban Goodstein, "Predicting Committee Behavior in Majority-Rule Voting Experiments," July, 1989.

89-26: Ken Binmore, Martin J. Osborne, Ariel Rubinstein, "Noncooperative Models of Bargaining," 1989.

89-27: Avery Katz, "Your Terms or Mine? The Duty to Read the Fine Print in Contracts," February 19, 1989. 


\section{Recent CREST Working Papers}

90-01: Hal R. Varian, "A Solution to the Problem of Externalities and Public Goods when Agents are Well-Informed," January 17, 1990.

90-02: Hal R. Varian, "Sequential Provision of Public Goods," January 17, 1990.

90-03: Hal R. Varian, "Goodness-of-Fit Optimizing Models," December 11, 1989.

90-04: Paul N. Courant, Alan Deardorff, "International Trade with Lumpy Countries, “ August 22, 1989.

90-05: Dilip K. Bhattacharyya, Jan Kmenta, "Testing Hypotheses about Regression Coefficients in Misspecified Models," December 15, 1989.

90-06: Greg Shaffer, "Slotting Allowances and Resale Price Maintenance: A Comparison of Facilitating Practices," November 1989.

90-07: Michelle J. White, “Why are Taxes So Complex and Who Benefits?" January 19, 1990.

90-08: Daniel P. O'Brien, “Endogenous Price Leadership: A Bargaining Model of International Telecommunications Settlements," May 1989.

90-09: Mark Bagnoli, Barton L. Lipman, "Stock Price Manipulation Through Takeover Bids," November 1989.

90-10: Ken Binmore, "Bargaining Theory Without Tears," December 1, 1989.

90-11: Hyun Song Shin, "Non-Partitional Information On Dynamic State Spaces and the Possibility of Speculation," December 1989. 


\begin{tabular}{ll} 
MichU & Bagnoli, Mark and \\
DeptE & Lipman, Barton L. \\
CenREST & "Stock price \\
W & manipulation through \\
take-9 & takeover bids" \\
\hline
\end{tabular}

ISSUED TO 
